\title{
Impact assessment research: use and misuse of habituation, sensitisation and tolerance in describing wildlife responses to anthropogenic stimuli
}

\author{
L. Bejder ${ }^{1, *}$, A. Samuels ${ }^{2,+}$, H. Whitehead ${ }^{3}$, H. Finn ${ }^{1}$, S. Allen ${ }^{1}$ \\ ${ }^{1}$ Murdoch University Cetacean Research Unit, Centre for Fish and Fisheries Research, Murdoch University, \\ South Street, Murdoch 6150, Western Australia \\ ${ }^{2}$ Woods Hole Oceanographic Institution, Woods Hole Road, Woods Hole, Massachusetts 02543, USA \\ ${ }^{3}$ Department of Biology, Dalhousie University, Oxford Street, Halifax, Nova Scotia B3H 4J1, Canada
}

\begin{abstract}
Studies on the effects of anthropogenic activity on wildlife aim to provide a sound scientific basis for management. However, misinterpretation of the theoretical basis for these studies can jeopardise this objective and lead to management outcomes that are detrimental to the wildlife they are intended to protect. Misapplication of the terms 'habituation', 'sensitisation' and 'tolerance' in impact studies, for example, can lead to fundamental misinterpretations of research findings. Habituation is often used incorrectly to refer to any form of moderation in wildlife response to human disturbance, rather than to describe a progressive reduction in response to stimuli that are perceived as neither aversive nor beneficial. This misinterpretation, when coupled with the widely held assumption that habituation has a positive or neutral outcome for animals, can lead to inappropriate decisions about the threats human interactions pose to wildlife. We review the conceptual framework for the use of habituation, sensitisation and tolerance, and provide a set of principles for their appropriate application in studies of behavioural responses to anthropogenic stimuli. We describe how cases of presumed habituation or sensitisation may actually represent differences in the tolerance levels of wildlife to anthropogenic activity. This distinction is vital because impact studies must address (1) the various mechanisms by which differing tolerance levels can occur; and (2) the range of explanations for habituationand sensitisation-type responses. We show that only one mechanism leads to true behavioural habituation (or sensitisation), while a range of mechanisms can lead to changes in tolerance.
\end{abstract}

KEY WORDS: Habituation · Sensitisation · Tolerance $\cdot$ Human disturbance $\cdot$ Wildlife management Conservation · Impact assessment

Resale or republication not permitted without written consent of the publisher

\section{INTRODUCTION}

Studies on the effects of anthropogenic disturbance on wildlife aim to provide the scientific basis for management decisions about how to regulate harmful or potentially harmful human activities. Many impact studies focus on the behavioural responses of wildlife to human stimuli, because behavioural attributes (for reasons of time, cost, logistics and ethics) are generally more amenable to study than other forms of response that may require long-term data (e.g. changes in reproductive success), capture of free-ranging animals (e.g. physiological responses), or elaborate experimental designs (e.g. anthropogenic noise). Studies of behavioural responses aim to (1) characterise cause (human activities) and effect (changes in wildlife behaviour) relationships; (2) assess the long-term biological significance of shortterm responses; and (3) ultimately provide practical information to inform management decisions. We suggest that these objectives are often compromised by the misapplication of the theoretical basis for interpreting behavioural responses to human disturbance, particularly in impact studies dealing with questions on behavioural habituation, sensitisation and tolerance.

The theoretical basis underlying behaviour-based impact studies should influence key components in- 
Table 1. Ecological characteristics that have been observed to change due to human disturbance

\begin{tabular}{|ll|}
\hline Characteristic & Example studies \\
\hline Home range size and habitat use & Altmann \& Muruthi (1988), McLellan \& Shackleton (1989), Albert \& Bowyer (1991), \\
& Bejder et al. (2006b) \\
Foraging behavior & Galicia \& Baldassarre (1997), Gander \& Ingold (1997) \\
Reproductive success & Safina \& Burger (1983), Giese (1996), Müllner et al. (2004), Bejder (2005) \\
Body condition and disease susceptibility & Altmann et al. (1993), Phillips-Conroy et al. (1993), Nizeyi et al. (1999), Woodford \\
& et al. (2002), Müllner et al. (2004) \\
Sex ratio & Clout et al. (2002) \\
Daily activity period & Griffiths \& van Schaik (1993) \\
Social development & de la Torre et al. (2000) \\
Mating system and social structure & Lacy \& Martins (2003) \\
\hline
\end{tabular}

cluding experimental design, analytical techniques, interpretation and translation into management. As with other areas of scientific inquiry, however, the misapplication of theoretical concepts can lead to fundamental flaws in both methods and conclusions. This is a factor that has led to calls for refinements in methodology in impact studies (e.g. Gill et al. 2001, Bejder \& Samuels 2003, Beale \& Monaghan 2004a) and for greater care in assessing the management implications of research findings (Bejder et al. 2006a). Here, we review the theoretical framework for behaviour-based impact studies, with particular attention to the correct use of the terms 'habituation', 'sensitisation' and 'tolerance'. We provide a set of principles for interpreting behavioural responses to human disturbance and for the application of research findings into management recommendations.

\section{PRINCIPLES FOR INTERPRETING BEHAVIOURAL RESPONSES TO HUMAN DISTURBANCE}

Principle 1: Responses of wildlife to human disturbance are complex and influenced by a range of factors. We live in a world where people and wildlife commonly come into close contact through industrial and agricultural development, expansion of human settlements, outdoor recreation and wildlife-based tourism. Studies on the impact of anthropogenic disturbance on wildlife play an integral role in managing conflicts and adverse impacts that occur when humans and wildlife interact. This is a formidable task because of the range of ways in which human disturbance can affect individual animals and wildlife populations (Table 1), and the diversity of attributes that may influence, either singly or in combination, the responsiveness of animals to human disturbance (Table 2) (see Samuels et al. 2003 for an overview).
Principle 2: Behavioural responses to human disturbance are best understood through a theoretical framework based on individual decision making. Evidence of the complexity of wildlife responses to human disturbance has led to criticism of traditional approaches to impact assessment research (e.g. Hill et al. 1997, Nisbet 2000, Gill et al. 2001, Bejder et al. 2006a). For example, recent work has shown that animals observed to vacate an area at the onset of a human activity are not a priori the only individuals affected by the disturbance, as had often been assumed in the past. Instead, segregation of animals may have already occurred prior to the onset of the disturbance, based on a continuum of individual tolerance, experience, or condition within a wildlife population. Gill et al. (2001, p. 266) encapsulated the complexity of behaviour that studies of wildlife responses to human disturbance would need to explain:

The decision of whether or not to move away from disturbed areas will be determined by factors such as the quality of the site currently being occupied, the distance to and quality of other suitable habitats, the relative risk of predation or density of competitors in different sites, and the investment that an individual has made in a site (for example, in establishing a territory, gaining dominance status or acquiring information).

In response to these concerns, impact assessment studies have begun to utilise models of individual decision making as the theoretical basis for understanding

Table 2. Attributes of animals that may influence their responsiveness to human disturbance

\begin{tabular}{|ll|}
\hline Attribute & Example studies \\
\hline Species & Gutzwiller et al. (1998) \\
Age & Stalmaster \& Newman (1978), Constantine (2001) \\
Sex & Williams et al. (2002), Lusseau (2003) \\
Reproductive condition & Culik \& Wilson (1995), Nellemann et al. (2000), \\
& Parent \& Weatherhead (2000) \\
Nutritional condition & Doenier et al. (1997), Beale \& Monaghan (2004a) \\
Prior experience & Burger \& Gochfeld (1999) \\
\hline
\end{tabular}


the behavioural outcomes of human disturbance (e.g. Gill et al. 1996, 2001, Gill \& Sutherland 2000, Frid \& Dill 2002, Stillman \& Goss-Custard 2002, Beale \& Monaghan 2004b). This approach applies aspects of evolutionary theory for decision making under the risk of predation to make predictions about how individuals will respond to nonlethal forms of human disturbance. The assumption here is that animals use analogous decision processes to evaluate responses to the risks presented by natural predators and those presented by anthropogenic agents of disturbance. Put differently, individuals will take the same ecological considerations into account when they experience human disturbance as they do when they perceive the risk of predation (Lima \& Dill 1990, Frid \& Dill 2002, Beale \& Monaghan 2004b). Thus, when disturbed, individuals will evaluate the costs and benefits of relocating to a less disturbed location based on factors such as (1) the quality of the area currently being occupied; (2) the distance, quality and availability of alternative sites; and (3) the relative predation risk and the density of competitors and associates or allies (Gill et al. 2001, Frid \& Dill 2002).

In the simplest scenario, an animal will decide to switch from short-term behavioural avoidance to longterm area avoidance when the cost of remaining and tolerating ongoing disturbance exceeds the benefits of continuing to occupy an otherwise preferred habitat. However, impact studies have shown that the decision of whether to relocate or not is complex, and a range of patterns in wildlife responses to human disturbance may be observed. Firstly, less tolerant individuals may move out of a disturbed area at the onset of human activity, thereby lowering the average density of animals and the average response within the disturbed area (Nellemann et al. 2000, Bejder et al. 2006a). Secondly, the animals that leave in the face of disturbance may be those that have sufficient body condition to expend the additional energy required to relocate (Stillman \& Goss-Custard 2002), while those that remain, because of inadequate energy reserves, may have no option but to stay within areas of chronic disturbance, regardless of possible long-term consequences (Gill et al. 2001). Thirdly, animals may have no other option but to stay if disturbances are concentrated in a critical habitat (e.g. an obligate breeding site), again regardless of the possible long-term consequences (Gill et al. 2001, Creel et al. 2002, Dyck \& Baydack 2004). Finally, animals may remain within a disturbed habitat either because they are socially relegated to these areas, lack sufficient experience to distinguish habitat quality, and/or have substantial investments in local social networks and territories.

A key advantage of an approach based on evolutionary theory is that it considers the consequences of dif- ferent wildlife responses in terms of their fitness costs, which is an attribute that allows impact studies to assess how particular behavioural decisions will influence individual reproductive success. Individual-level effects can then be translated into changes in demographic parameters of populations, thus allowing for an assessment of the biological significance of particular human disturbances.

Principle 3: Behavioural habituation and related concepts are often misunderstood, which can lead to adverse wildlife management outcomes. While the application of evolutionary theory to impact assessment research has contributed to a renewed focus on individuals as the appropriate unit of study, concepts from other fields have also influenced our understanding of how individual animals respond to human disturbance. The ethological concepts of 'habituation', 'sensitisation' and 'tolerance', for example, have become increasingly used within the peer-reviewed and grey literature as a way of describing how animals respond to ongoing disturbances. However, these concepts are applied in ways that are variously incorrect, imprecise and sometimes interchangeable. Apparent 'habituation' to a human activity, in particular, is often claimed as a response of wildlife that is repeatedly exposed to anthropogenic disturbance.

There are 2 basic problems with how the scientific discourse involving the concept of behavioural habituation is currently structured and how this concept is applied to wildlife management issues. The first problem is that the terms 'habituation' and 'habituated' are often incorrectly defined, leading to misinterpretations of behavioural data and inappropriate applications of the terms. Claims of habituation are usually based on quantitative or anecdotal observations that the behaviour of animals appears to become progressively less influenced by the presence of particular anthropogenic stimuli. This understanding follows from the common, but insufficient, conception that habituation simply reflects a stimulus-specific response that weakens after repeated exposure to the stimuli. Principles 4 to 6 of this paper discuss a more nuanced and appropriate use for this concept.

The second problem with the current use of habituation is the general perception that evidence of habituation indicates that a particular disturbance has little or no effect, which may support conclusions that animals are not adversely affected by human activities to which they are considered habituated. Alternatively, habituation may even be seen as a desirable outcome, as when tourism operators seek to habituate certain animals so that they can be closely approached or handled (e.g. Nisbet 2000). Researchers may also seek to habituate certain animals so that they can observe behaviour that is relatively unaffected by their 
own presence (e.g. Goodall 1986, Tutin \& Fernandez 1991, Johns 1996).

Without debating the pros and cons of habituating wildlife to humans here, we note that there is considerable disagreement as to whether or not habituation compromises the well-being of wildlife (e.g. McLellan \& Shackleton 1989, Spradlin et al. 1998, Nisbet 2000, Woodford et al. 2002). There is evidence that behavioural habituation can result in harmful outcomes for wildlife through, for example, increased exposure to disease or loss of wariness to vehicular activity (Spradlin et al. 1998, Stone \& Yoshinaga 2000, Woodford et al. 2002). This suggests that any activity that directly or indirectly habituates wildlife to human contact should be carefully considered. Further, we emphasize that the inappropriate application of the term 'habituation' can mislead wildlife managers to conclude that particular human activities have neutral, or even benign, consequences for wildlife when, in fact, the effects of these activities are detrimental. Harmful effects may therefore go unrecognized, with management strategies calling for either no corrective action, an easing of conservation efforts or even an increase in the activity (e.g. Griffin et al. 2007).

Principle 4: Impact studies must apply correct and consistent definitions for habituation, sensitisation and tolerance. Habituation and sensitisation are adaptive behavioural modifications exhibited by individual animals in response to exposure to a stimulus that is repetitious or continuous. As these processes occur over time, habituation and sensitisation do not refer to specific behavioural responses, as is commonly understood. Behavioural habituation is

the relative persistent waning of a response as a result of repeated stimulation, which is not followed by any kind of reinforcement

(Thorpe 1963, p. 61) (Table 3). Habituation is, therefore, a process involving a reduction in response over time as individuals learn that there are neither adverse nor beneficial consequences of the occurrence of the stimulus. Sensitisation refers to the opposite phenomenon:

increased behavioural responsiveness over time when animals learn that a repeated or ongoing stimulus has significant consequences for the animal

(Richardson et al. 1995, p. 543) (Table 3). Individuals that are sensitised to human stimuli will thus exhibit a progressive intensification of their response to these stimuli, e.g. by fleeing further and faster when they encounter the stimulus, or by exhibiting responses at progressively lower stimulus intensities. Since habituation and sensitisation constitute learning processes that are ongoing, they reflect an individual's cumulative experience with humans, including the number and outcome of its exposures to anthropogenic stimuli over the course of its lifetime (Knight \& Temple 1995).

Principle 5: Impact studies typically document differences in levels of tolerance, not habituation or sensitisation. While habituation, when correctly understood, represents a learning process over time, the term is often misused to describe any observed moderation in wildlife responses to a human disturbance (e.g. Sini et al. 2005, Griffin et al. 2007, Holmes et al. 2006). In many cases, however, the moderation in response will involve increases in individual tolerance levels to the disturbance, rather than habituation to it (Nisbet 2000). Tolerance is defined as 'the intensity of disturbance that an individual tolerates without responding in a defined way' (Nisbet 2000, p. 315) (Table 3). Tolerance levels can be measured instantaneously and are, therefore, more readily demonstrated than the longerterm processes of habituation or sensitisation. In fact, habituation and sensitisation are identified, and distinguished from each other, by the direction of change indicated by repeated measures of tolerance taken over time. Thus, over the course of a habituation process, individual tolerance levels will increase, whereas tolerance levels will conversely decrease as individuals become sensitised to specific stimuli.

It is vital that impact studies clearly distinguish between habituation/sensitisation as ongoing behavioural 'processes' and tolerance as a behavioural 'state' that can be measured at a single point in time. For example, a single observation showing that animals in one group are more tolerant to a particular disturbance than those in another group only shows that the groups differ in their tolerance to the disturbance. While the observation provides one piece of evidence that habituation may have occurred in the more tolerant group, confirmation that habituation (or sensitisation) had occurred would require long-term sequential measurements of responses by individuals to controlled stimuli (Nisbet 2000). This is a rigorous assessment process that has rarely been utilised in field studies (but see Tutin \& Fernandez 1991, Johns 1996). Practical and financial limits generally constrain the vast majority of impact assessment studies to observations covering a limited number of points in time, thus imposing inherent restrictions on their ability to document habituation and sensitisation.

As a result of these limitations, impact studies of human disturbance typically follow one of 2 study designs: (1) instantaneous (i.e. one observation at a single point in time) comparison of behavioural responses between communities that differ in their histories of exposure to disturbance (e.g. the duration, frequency and intensity of exposure) (Fig. 1A), or (2) sequential (i.e. a series of observations) comparison of responses within one community at multiple points in time (Fig. 1B). For example, the 
Table 3. Working definitions for categories of behavioral response and requirements for their demonstration

\begin{tabular}{|c|c|c|c|}
\hline Term & Definition & $\begin{array}{l}\text { Time course } \\
\text { of response }\end{array}$ & $\begin{array}{l}\text { Requisites to demonstrate } \\
\text { response }\end{array}$ \\
\hline Habituation & $\begin{array}{l}\text { Relative persistent waning of a response as a result of } \\
\text { repeated stimulation which is not followed by any kind } \\
\text { of reinforcement (Thorpe 1963, p. 61) }\end{array}$ & $\begin{array}{l}\text { Longitudinal } \\
\text { process }\end{array}$ & $\begin{array}{l}\text { Sequential measures taken from } \\
\text { the same individuals over time }\end{array}$ \\
\hline Sensitisation & $\begin{array}{l}\text { Increased behavioural responsiveness over time when } \\
\text { animals learn that a repeated or ongoing stimulus has } \\
\text { significant consequences for the animal } \\
\text { (Richardson et al. 1995, p. 543) }\end{array}$ & $\begin{array}{l}\text { Longitudinal } \\
\text { process }\end{array}$ & $\begin{array}{l}\text { Sequential measures taken from } \\
\text { the same individuals over time }\end{array}$ \\
\hline Tolerance & $\begin{array}{l}\text { Intensity of disturbance that an individual. ...tolerates } \\
\text { without responding in a defined way (Nisbet 2000, p. 315) }\end{array}$ & State & $\begin{array}{l}\text { Instantaneous measurement of } \\
\text { many individuals at one time }\end{array}$ \\
\hline
\end{tabular}

goal in Fig. 1A would be to evaluate the effects of anthropogenic activity on animals that have been exposed to a given stimulus (treatment group) by comparing them with animals having little or no history of exposure (control group). In Fig. 1B, members of the same community would be sampled at different durations of exposure.

In both designs, documenting differing levels of tolerance within or between communities of animals is readily achieved. However, proof of behavioural habituation or sensitisation is feasible only when employing the latter design, and only when the same individual

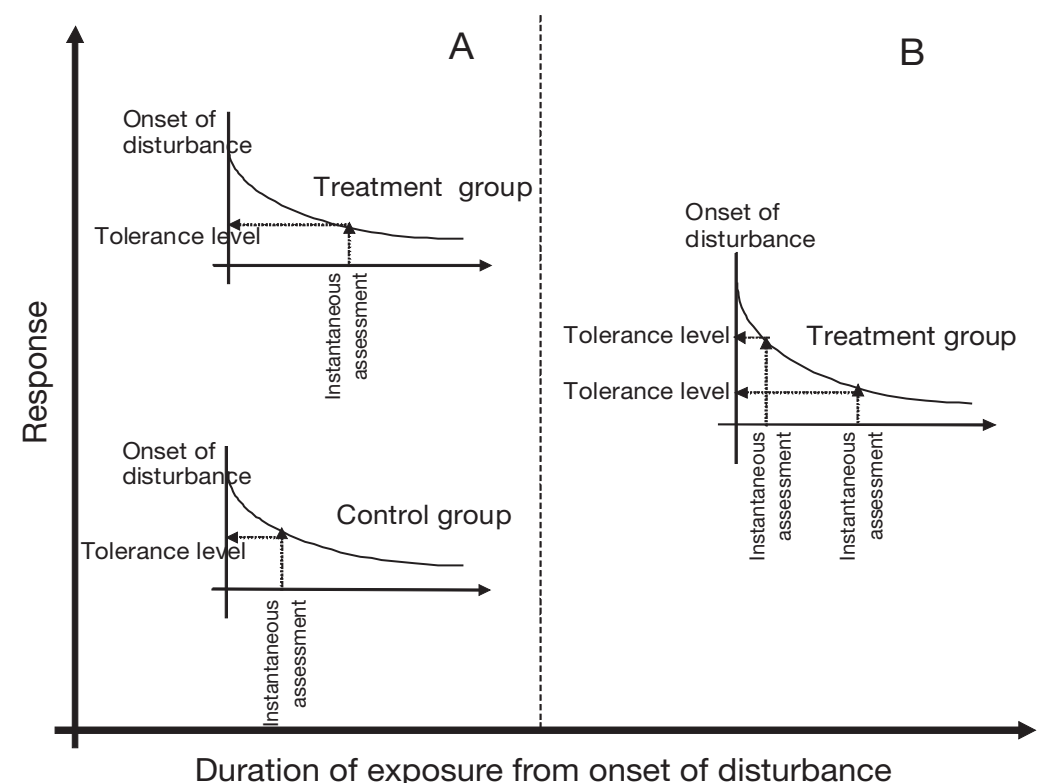

Fig. 1. Examples depicting 2 study designs typically used for assessing anthropogenic impact on wildlife. The origin represents the time of onset of the disturbance factor; hence, the $x$-axis denotes duration of exposure to the stimulus, and the $y$-axis represents corresponding levels of response to the stimulus. (A) Instantaneous comparison (at one point in time) of responses between treatment and control groups with different durations of exposure. (B) Sequential comparison (at 2 points in time) of responses measured within one community at different times of exposure. Note direction of $y$-axes in inset figures: tolerance levels increase as response levels decrease (large $y$-axis) animals are sampled through time. The second criterion, in particular, is seldom met. Most studies do not individually identify and monitor individuals - a consideration which precludes the ability to detect behavioural change in individuals - even when sequential observations are taken within a community. Thus, unless studies adopt a long-term experimental design nvolving sequential sampling of the same individuals at different levels of exposure to a disturbance, they will be unable to meet the conditions required to detect behavioural habituation or sensitisation.

Principle 6: When habituation- and sensitisation-type responses occur, a range of potential explanatory mechanisms should be considered. Fig. 2 depicts a 'habituation-type' response in which an ongoing stimulus (disturbance) that causes a change in an animal's behaviour, as measured by the response variable ( $y$-axis), is introduced. With repeated exposure to the stimulus over time ( $x$-axis), the intensity of the response declines and ultimately approaches the pre-stimulus level for the particular behaviour. In impact studies, the response variable ( $y$-axis) is often a measure of the mean population response based on measurements of the response variable for randomly chosen members of the population at intervals following the introduction of the stimulus. A parallel but opposite schema could be generated for a 'sensitisation-type' response.

The habituation-type response shown in Fig. 2 can also be used to examine (a) the higher tolerance level of the treatment group in Fig. 1A (the treatment group appears to show a reduced responsiveness to the stimulus relative to the control group); and (b) the higher tolerance level of the treatment group at the second assessment 


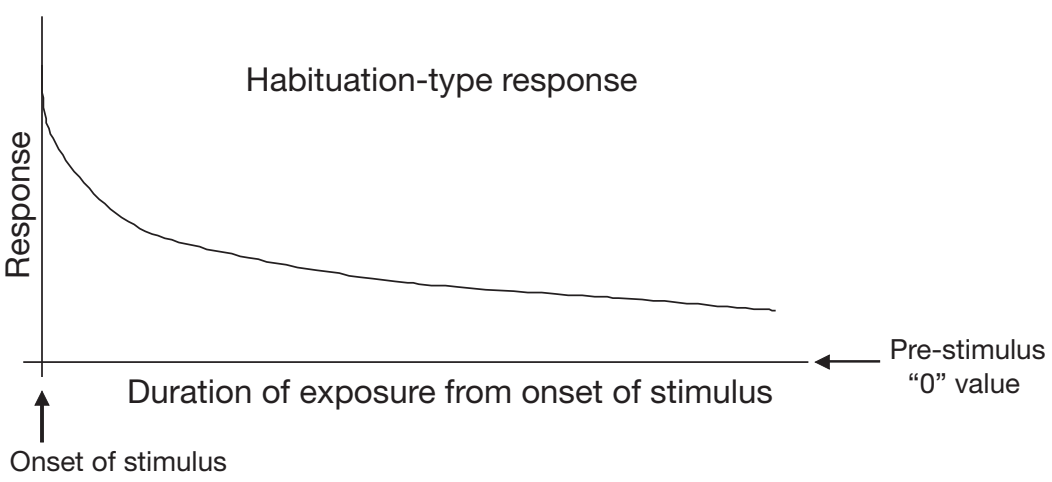

Fig. 2. Simplified illustration of 'habituation-type' response. As in Fig. 1, the origin represents the time of onset of the stimulus; hence, the $x$-axis denotes duration of exposure to the stimulus and the $y$-axis represents corresponding levels of response to the stimulus

interval (the treatment group appears to show a reduced responsiveness to the stimulus after greater cumulative exposure to the stimulus). In fact, the explanatory mechanisms for evaluating an apparent habituation-type response in one population are, with one exception, functionally similar to those used for examining how differences in observed tolerance levels between separate control and treatment groups can occur. There are at least 4 different explanatory mechanisms (scenarios) that could account for evidence of a habituation-type response.

Scenario 1: Learning. Individual animals learn, with repeated exposure, not to respond to a given stimulus, i.e. they show true behavioural habituation. In the case of Fig. 1A, this means that members of the treatment group have become more tolerant to disturbance through a gradual process of behavioural habituation.

Scenario 2: Displacement. The movement of less tolerant individuals out of a region in response to human activity can effect a reduction in the average density of animals and a more moderate average response among animals within the disturbed area (Fowler 1999, Bejder et al. 2006a,b). For example, if the less tolerant members of a group segregate themselves prior to the onset of an assessment interval, this would cause the impact group (i.e. the group on which measurements are taken) to be biased towards more tolerant individuals. As a consequence, the assessment would only measure the responses of more tolerant individuals present at the study site at the time of sampling and not the avoidance responses of the (already relocated) less tolerant group members (e.g. Griffiths \& van Schaik 1993, Fowler 1999, Bejder et al. 2006a,b).

Scenario 3: Physiology. Animals may exhibit reduced responsiveness to a given stimulus because the repeated or prolonged exposure to that stimulus has caused physiological impairment, e.g. deafening in the case of a loud acoustic stimulus.
Scenario 4: Ecology. Ecological factors could account for the presence or absence of habituation-type responses. For example, study sites may not have a suitable adjacent habitat to which animals can relocate, thus forcing individuals to remain in proximity to a disturbance they would otherwise avoid (Gill et al. 2001, Frid \& Dill 2002). In situations where habitat differences may occur between control and treatment sites, criteria to assess habitat suitability and availability, including e.g. abundance of prey and/or shelter, predation risk and social factors, need to be developed. Alternatively, behavioural changes appearing to indicate a reduced responsiveness to a disturbance may instead reflect adjustments to other features of their habitat to which animals may have responded. For example, the behaviour of study animals may change as they respond to the habituation of prey species to the disturbance, or to the displacement of predators because of the disturbance.

Three important conclusions arise from consideration of the potential explanatory mechanisms for habituation-type responses. Firstly, habituation occurs in only one of the 4 scenarios (Scenario 1). As discussed in Principle 5, confirmation of the occurrence of habituation would require sequential sampling of the same individuals showing reduced responsiveness to the stimuli over time. Secondly, the interpretation of habituationtype responses is complex and not well-served by a colloquial understanding of the terms habituation and sensitisation. For example, the failure to understand habituation as a process could lead to the premature conclusion that any evidence of a moderation in response or difference in responsiveness between groups constitutes habituation. When coupled with the perception that habituation indicates that animals are unaffected by a disturbance, this line of reasoning would support the equally inappropriate conclusion that a disturbance has no detrimental impacts. While it is possible that these conclusions may be correct, they cannot be accepted without considering other explanations and, in all likelihood, obtaining further information.

Finally, the mechanisms that do not involve true habituation are unlikely to denote neutral or beneficial outcomes for wildlife affected by disturbance. Even in cases where ecological factors may not have a direct impact on study populations, they indicate that human disturbance has caused some form of ecological change within their habitat, which may have indirect effects that are difficult to predict. The outcomes of physiological damage and displacement are likely to be detrimental, since they indicate that some form of 
individual impairment or change in the selective factors operating on the population has occurred, which may reduce the reproductive success of, at the least, individuals.

\section{Behavioural habituation can only be inferred for monitored response variables}

Impact studies are typically limited in their ability to demonstrate a waning or waxing of wildlife response to human activity because they are often brief in duration and/or unable to monitor known individuals. Practical and financial constraints are likely to influence which individuals can be sampled and how often, and also what behaviours can be assessed as response variables. Most studies are restricted to monitoring short-term, observable, behavioural responses rather than, for example, physiological responses that typically have no visible, external indicator and are thus not readily detectable in free-ranging animals. This emphasis on one modality of response effectively limits the scope of conclusions that can be drawn from the investigation. Accordingly, even after other explanatory mechanisms have been ruled out and true behavioural habituation has been confirmed, findings must still be handled with caution because the conclusion is likely to be specific only to the response variable that has been monitored.

The most effective course of action in impact studies would therefore be to complement behavioural assessment with monitoring of physical condition and of physiological measures such as heart rate, body temperature and/or hormonal levels. The value of this approach has been affirmed by studies in which behavioural and physiological responses were monitored simultaneously. Disconcertingly, these studies have indicated that changes in behaviour do not always provide a sufficiently sensitive or timely indicator of a response to a stimulus, or indeed the effects of disturbance if considered in isolation (Beale \& Monaghan 2004a,b). For example, several studies have indicated that physiological evidence of a response could be detected in animals even when they exhibited little or no behavioural reaction or sign of disturbance (Moen et al. 1982, Culik et al. 1990, Wilson et al. 1991, Nimon et al. 1995, Regel \& Putz 1997, Ratz \& Thompson 1999, Müllner et al. 2004). It is clear that animals can respond in one modality but not in another; thus, it is likely that animals may become habituated in one modality but not in another.

\section{CONCLUSION}

Studies of the effects of human activity on wildlife have often operated under the assumption that (1) the behavioural habituation of wildlife to anthropogenic stimuli is relatively easy to demonstrate, and (2) habituation-type responses imply an absence of detrimental consequences for targeted animals. In this paper, we have shown that neither assumption is entirely correct and that the misinterpretation of scientific findings resulting from reliance on these premises can lead to inappropriate conclusions and potentially detrimental consequences for wildlife. The classification of a wildlife response as 'habituation' should not be made without considerable scrutiny; thus, we urge wildlife biologists and managers to use care in assigning such a label if stringent requirements for sequential monitoring of individual responses to a given stimulus have not been met. We further caution against extrapolating evidence of habituation to a specific response variable to other variables that have not been assessed, or indeed failing to consider the range of explanatory mechanisms that could account for behavioural habituation or sensitisation. Instead, we suggest that in many instances, a designation of 'varying levels of tolerance', which carries no colloquial or a priori preconceptions, is more appropriate.

Dedication. With great sadness, we inform readers of the passing of A. Samuels. Amy's vigour, rigour and integrity in the field, in writing and in her personal life were inspirational and she will be greatly missed, both as a friend and a colleague. In this contribution to the literature, her values live on.

Acknowledgements. We thank B. Chicoski, R. Constantine, L. Engleby, D. Lusseau, R. Williams and A. Mehta for stimulating us to write this essay and for helping us to obtain sources for it. M. Leonard, V. LoLordo and S. Yin provided helpful comments on previous versions of the essay. This essay is a by-product of research funded by the Danish Research Agency, The Western Australian Department of Conservation and Land Management, the PADI Foundation, the US Marine Mammal Commission, and the Patrick Lett Fund.

\section{LITERATURE CITED}

Albert DM, Bowyer RT (1991) Factors related to grizzly bear-human interactions in Denali National Park. Wildl Soc Bull 19:339-349

Altmann J, Muruthi P (1988) Differences in daily life between semiprovisioned and wild-feeding baboons. Am J Primatol 15:213-221

Altmann J, Schoeller D, Altmann SA, Muruthi P, Sapolsky RM (1993) Body size and fatness of free-living baboons reflect food availability and activity levels. Am J Primatol 30: 149-161

- Beale CM, Monaghan P (2004a) Behavioural responses to human disturbance: a matter of choice. Anim Behav 68: 1065-1069

> Beale CM, Monaghan P (2004b) Human disturbance: people as predation-free predators? J Appl Ecol 41:335-343

Bejder L (2005) Linking short and long-term effects of naturebased tourism on cetaceans. PhD dissertation, Dalhousie University, Halifax, NS 
Bejder L, Samuels A (2003) Evaluating impacts of naturebased tourism on cetaceans. In: Gales N, Hindell M, Kirkwood R (eds) Marine mammals: fisheries, tourism and management issues. CSIRO Publishing, Collingwood, p 229-256

Bejder L, Samuels A, Whitehead H, Gales N (2006a) Interpreting short-term behavioural responses to disturbance within a longitudinal perspective. Anim Behav 72: 1149-1158

Bejder L, Samuels A, Whitehead H, Gales N and others (2006b) Decline in relative abundance of bottlenose dolphins exposed to long-term disturbance. Conserv Biol 20: 1791-1798

Burger J, Gochfeld M (1999) Role of human disturbance in response behavior of Laysan albatrosses (Diomedea immutabilis). Bird Behav 13:23-30

Clout MN, Elliott GP, Robertson BC (2002) Effects of supplementary feeding on the offspring sex ratio of kakapo: a dilemma for the conservation of a polygynous parrot. Biol Conserv 107:13-18

Constantine R (2001) Increased avoidance of swimmers by wild bottlenose dolphins (Tursiops truncatus) due to longterm exposure to swim-with-dolphin tourism. Mar Mamm Sci 17:689-702

Creel S, Fox JE, Hardy A, Sands J, Garrott B, Peterson RO (2002) Snowmobile activity and glucocorticoid stress responses in wolves and elk. Conserv Biol 16:809-814

Culik BM, Wilson RP (1995) Penguins disturbed by tourists. Nature 376:301-302

Culik B, Adelung D, Woakes AJ (1990) The effect of disturbance on the heart rate and behaviour of Adelie penguins $\left(P_{Y}-\right.$ goscelis adeliae) during the breeding season. In: Kerry KR, Hempel G (eds) Antarctic ecosystems: ecological change and conservation. Springer-Verlag, Berlin, p 177-182

de la Torre S, Snowdon CT, Bejarano M (2000) Effects of human activities on wild pygmy marmosets in Ecuadorian Amazonia. Biol Conserv 94:153-163

Doenier PB, DelGiudice GD, Riggs MR (1997) Effects of winter supplemental feeding on browse consumption by white-tailed deer. Wildl Soc Bull 25:235-243

> Dyck MG, Baydack RK (2004) Vigilance behaviour of polar bears (Ursus maritimus) in the context of wildlife-viewing activities at Churchill, Manitoba, Canada. Biol Conserv 116:343-350

Fowler GS (1999) Behavioral and hormonal responses of Magellanic penguins (Spheniscus magellanicus) to tourism and nest site visitation. Biol Conserv 90:143-149

Frid A, Dill L (2002) Human-caused disturbance stimuli as a form of predation risk. Conserv Ecology 6:11-26

Galicia E, Baldassarre GA (1997) Effects of motorized tourboats on the behavior of nonbreeding American flamingos in Yucatan, Mexico. Conserv Biol 11:1159-1165

Gander H, Ingold P (1997) Reactions of male alpine chamois (Rupicapra r. rupicapra) to hikers, joggers and mountainbikers. Biol Conserv 79:107-109

Giese M (1996) Effects of human activity on Adélie penguin Pygoscelis adeliae breeding success. Biol Conserv 75: 157-164

Gill JA, Sutherland WJ (2000) The role of behavioural decision-making in predicting the consequences of human disturbance. In: Gosling LM, Sutherland WJ (eds) Behaviour and conservation. Cambridge University Press, Cambridge

> Gill JA, Sutherland WJ, Watkinson AR (1996) A method to quantify the effects of human disturbance on animal populations. J Appl Ecol 33:786-792

Gill JA, Norris K, Sutherland WJ (2001) Why behavioural responses may not reflect the population consequences of human disturbance. Biol Conserv 97:265-268

Goodall J (1986) The chimpanzees of Gombe: patterns of behavior. Bellknap Press of Harvard University Press, Cambridge, MA

Griffin SC, Valois T, Taper ML, Mills LS (2007) Effects of tourists on behavior and demography of olympic marmots. Conserv Biol 21:1070-1081

Griffiths M, van Schaik CP (1993) The impact of human traffic on the abundance and activity periods of Sumatran rain forest wildlife. Conserv Biol 7:623-626

Gutzwiller KJ, Marcum HA, Harvey HB, Roth JD, Anderson $\mathrm{SH}$ (1998) Bird tolerance to human intrusion in Wyoming montane forests. Condor 100:519-527

Hill D, Hockin D, Price D, Tucker G, Morris R, Treweek J (1997) Bird disturbance: improving the quality and utility of disturbance research. J Appl Ecol 34:275-288

Holmes ND, Giese M, Achurch H, Robinson S, Kriwoken LK (2006) Behaviour and breeding success of gentoo penguins Pygoscelis papua in areas of low and high human activity. Polar Biol 29:399-412

Johns BG (1996) Responses of chimpanzees to habituation and tourism in the Kibale Forest, Uganda. Biol Conserv 78: $257-262$

Knight RL, Temple SA (1995) Origin of wildlife responses to recreationists. In: Knight RL, Gutzwiller KJ (eds) Wildlife and recreationists: coexistence through management and research. Island Press, Washington, DC, p 81-91

- Lacy KE, Martins EP (2003) The effect of anthropogenic habitat usage on the social behaviour of a vulnerable species, Cyclura nubila. Anim Conserv 6:3-9

> Lima SL, Dill LM (1990) Behavioral decisions made under the risk of predation: a review and prospectus. Can J Zool 68: $619-640$

Lusseau D (2003) Male and female bottlenose dolphins Tursiops spp. have different strategies to avoid interactions with tour boats in Doubtful Sound, New Zealand. Mar Ecol Prog Ser 257:267-274

McLellan BN, Shackleton DM (1989) Immediate reactions of grizzly bears to human activities. Wildl Soc Bull 17: 269-274

Moen AN, Whittemore S, Buxton B (1982) Effects of disturbance by snowmobiles on heart rate of captive whitetailed deer. NY Fish Game J 29:177-183

> Müllner A, Linsenmair KE, Wikelski M (2004) Exposure to ecotourism reduces survival and affects stress response in hoatzin chicks (Opisthocomus hoazin). Biol Conserv 118: 549-558

Nellemann C, Jordhoy P, Stoen OG, Strand O (2000) Cumulative impacts of tourist resorts on wild reindeer (Rangifer tarandus tarandus) during winter. Arctic 53:9-17

> Nimon AJ, Schroter RC, Stonehouse B (1995) Heart rate of disturbed penguins. Nature 374:415

Nisbet ICT (2000) Disturbance, habituation, and management of waterbird colonies. Waterbirds 23:312-332

Nizeyi JB, Mwebe R, Nanteza A, Cranfield MR, Kalema GRNN, Graczyk TK (1999) Cryptosporidium sp. and Giardia sp. infections in mountain gorillas (Gorilla gorilla beringei) of the Bwindi Impenetrable National Park, Uganda. J Parasitol 85:1084-1088

> Parent C, Weatherhead PJ (2000) Behavioral and life history responses of eastern massasauga rattlesnakes (Sistrurus catenatus catenatus) to human disturbance. Oecologia 125:170-178

Phillips-Conroy JE, Hildebolt CF, Altmann J, Jolly CJ, Muruthi P (1993) Periodontal health in free-ranging baboons of Ethiopia and Kenya. Am J Phys Anthropol 90: 
359-371

Ratz H, Thompson C (1999) Who is watching whom? Checks for impacts of tourists on yellow-eyed penguins, Megadyptes antipodes. Mar Ornithol 27:205-210

Regel J, Putz K (1997) Effect of human disturbance on body temperature and energy expenditure in penguins. Polar Biol 18:246-253

Richardson WJ, Greene CR, Malme CI, Thomsen DH, Moore SE, Würsig B (eds) (1995) Marine mammals and noise. Academic Press, San Diego, CA

Safina C, Burger J (1983) Effects of human disturbance on reproductive success in the black skimmer. Condor 85: $164-171$

Samuels A, Bejder L, Chicoski B, Engleby L, Mehta A (2003) An annotated bibliography pertaining to human interaction with terrestrial wildlife. Report to the Marine Mammal Commission \#T74463123, Bethesda, MD

Sini MI, Canning SJ, Stockin KA, Pierce GJ (2005) Bottlenose dolphins around Aberdeen harbour, north-east Scotland: a short study of habitat utilization and the potential effects of boat traffic. J Mar Biol Assoc UK 85: $1547-1554$

Spradlin TR, Terbush AD, Smullen WS (1998) NMFS update on human/dolphin interactions in the wild. Soundings. Mag Int Mar Anim Trainers Assoc 23:25-27

Submitted: July 11, 2008; Accepted: February 16, 2009
Stalmaster MV, Newman JR (1978) Behavioral responses of wintering bald eagles to human activity. J Wildl Manag 42:506-513

> Stillman RA, Goss-Custard JD (2002) Seasonal changes in the response of oystercatchers Haematopus ostralegus to human disturbance. J Avian Biol 33:358-365

Stone GS, Yoshinaga A (2000) Hector's dolphin Cephalorhynchus hectori calf mortalities may indicate new risks from boat traffic and habituation. Pac Conserv Biol 6: $162-170$

Thorpe WH (1963) Learning and instinct in animals. Methuen, London

Tutin CEG, Fernandez M (1991) Responses of wild chimpanzees and gorillas to the arrival of primatologists: behaviour observed during habituation. In: Box HO (ed) Primate responses to environmental change. Chapman \& Hall, London, p 187-197

Williams R, Trites AW, Bain DE (2002) Behavioural responses of killer whales (Orcinus orca) to whale-watching boats: opportunistic observations and experimental approaches. J Zool 256:255-270

Wilson RP, Culik B, Danfeld R, Adelung D (1991) People in Antarctica - How much do Adélie penguins Pygoscelis adeliae care? Polar Biol 11:363-370

Woodford MH, Butynski TM, Karesh WB (2002) Habituating the great apes: the disease risks. Oryx 36:153-160

Proofs received from author(s): March 23, 2009 